\title{
High prevalence of multidrug-resistant MRSA in a tertiary care hospital of northern India
}

\author{
Hare Krishna Tiwari' \\ Darshan Sapkota ${ }^{2}$ \\ Malaya Ranjan Sen' \\ 'Department of Microbiology, \\ Institute of Medical Sciences, Banaras \\ Hindu University, Varanasi, UP, India; \\ ${ }^{2}$ Department of Microbiology, \\ Universal College of Medical Sciences, \\ Bhairahawa, Nepal
}

\begin{abstract}
Methicillin-resistant Staphylococcus aureus (MRSA) is an important nosocomial and community pathogen. The objectives of this study were to estimate the prevalence of multidrugresistant MRSA strains in clinical specimens and to investigate the sensitivity pattern of these strains against various antibiotics used for treating hospitalized and out patients. Strains were identified using standard procedures, and their sensitivity pattern was investigated using such techniques as disc diffusion, minimum inhibitory concentration (MIC), and the mecA gene PCR. Among 783 isolates of S. aureus, 301 (38.44\%) were methicillin-resistant, of which $217(72.1 \%)$ were found to be multidrug-resistant. Almost all MRSA strains were resistant to penicillin, $95.68 \%$ were resistant to cotrimoxazole, $92.36 \%$ were resistant to chloramphenicol, $90.7 \%$ were resistant to norfloxacin, $76.1 \%$ were resistant to tetracycline, and $75.75 \%$ were resistant to ciprofloxacin. Vancomycin was the most effective drug, with only $0.33 \%$ of MRSA strains being resistant to it. It is concluded that antibiotics other than vancomycin can be used as anti-MRSA agents after a sensitivity test so as to preclude the emergence of resistance to it and that prevailing problems in chemotherapy will escalate unless indiscriminate and irrational usage of antibiotics is checked.
\end{abstract}

Keywords: multidrug-resistant MRSA, prevalence, India

\section{Introduction}

Infections caused by Staphylococcus aureus have a poorer prognosis when the infecting strain is MRSA (Cosgrove et al 2003). Since its first report in 1961 (Jevons 1961), the strain has been progressively causing increased mortality, morbidity, and health care costs with skin and soft tissue infections, ventilator-associated pneumonia, catheter associated bacteremia, and many other infections in hospitals and communities. First detected in hospitals, methicillin resistance is now increasingly recognized in the community (Chambers 2001).

In addition to dire consequences of infections, MRSA strains are important for their resistance to many other commonly used antibiotics and the emergence of resistance to vancomycin, the drug that has been used to treat MRSA infections for more than three decades. Thus, it is immensely important to study the antibiogram of MRSA in a given hospital so that the results of such studies can be exploited to minimize the irrational use of vancomycin when other antibiotics would cure an infection. Reports of emergence of vancomycin resistance in S. aureus from India (Assadullah et al 2003; Tiwari and Sen 2006; Saha et al 2008) further justify this necessity.

The prevalence of MRSA has varied from hospital to hospital in various countries. About $40 \%$ of S. aureus infections acquired in large US hospitals (500 or more beds) are methicillin-resistant (Red Book 2003). Prevalence is constantly soaring in many countries, and in some hospitals, more than half of all $S$. aureus disease isolates are MRSA (Voss and Doebbeling 1995). In many American and European hospitals, the percentage of MRSA has ranged from $29 \%$ to $35 \%$ of all clinical isolates. Meanwhile, 
information from developing countries is provided only by relatively sophisticated hospitals (Degerli et al 2000; Gastmeier et al 2000; Santos et al 2000); as a consequence, the data on MRSA prevalence, most of which are from developed countries, are inadequate in estimating the overall global distribution (Pulimood et al 1996; Verma et al 2000; Majumder et al 2001; Tahnkiwale et al 2002; Anupurba et al 2003; Mohanty et al 2004; Rajaduraipandi et al 2006; Mehta et al 2007; Mulla et al 2007).

The present study uncovers the prevalence of multidrugresistant MRSA strains and investigates their antibiotic sensitivity pattern in a tertiary care hospital of northern India.

\section{Material and methods}

During August 2002 and June 2006, a total of 783 strains of S. aureus were isolated from various specimens of different patients visiting and admitted at Sir Sundar Lal Hospital, a 972 bed tertiary care teaching hospital of Banaras Hindu University at Varanasi, India.

\section{Isolation and identification of staphylococci from clinical specimens}

All specimens, except urine for which cystine lactose electrolyte deficient agar (HiMedia, New Delhi, India) was used, were cultured on blood agar and MacConkey agar (HiMedia, New Delhi, India). S. aureus was identified and differentiated from related organisms on the basis of colony morphology, Gram staining, catalase test, tube coagulase test using rabbit plasma, slidex staph plus (Biomerurix India Ltd, New Delhi, India), thermonuclease and acetoin production, and mannitol fermentation (Barid 1996). Using growth on blood agar, all the strains were subjected to the following tests. S. aureus ATCC 25923 (mecA negative) and ATCC 43300 (mecA positive) were used for the quality control of all the tests.

\section{Disc diffusion test by Kirby-Bauer method}

Mueller-Hinton agar (MHA) plates were overlaid with the saline suspension of a strain (turbidity matching 0.5 McFarland standard), and the following antibiotic discs procured from HiMedia, India were placed on the plate after 10 minutes, with six discs on a plate: penicillin (10 U), oxacillin $(1 \mu \mathrm{g})$, gentamicin $(10 \mu \mathrm{g})$, tobramycin $(30 \mu \mathrm{g})$, amikacin $(30 \mu \mathrm{g})$, netilmicin $(30 \mu \mathrm{g})$, norfloxacin $(10 \mu \mathrm{g})$, ciprofloxacin $(5 \mu \mathrm{g})$, chloramphenicol $(30 \mu \mathrm{g})$, erythromycin $(15 \mu \mathrm{g})$, tetracycline $(15 \mu \mathrm{g})$, trimethoprim/sulfamethoxazole $(1.25 / 23.75 \mu \mathrm{g})$, nitrofurantoin $(300 \mu \mathrm{g})$, vancomycin $(30 \mu \mathrm{g})$, and sulbactam/cefoperazone (30/75 $\mu \mathrm{g})$. After 24 and $48 \mathrm{~h}$ of incubation at $35^{\circ} \mathrm{C}$, the plates were read using the NCCLS break-points as reference (NCCLS 2004).

\section{Oxacillin MIC test}

Gradient plates of MHA containing 2\% $\mathrm{NaCl}$ were prepared with doubling dilutions (from $0.25 \mu \mathrm{g} / \mathrm{ml}$ to $256 \mu \mathrm{g} / \mathrm{ml}$ ) of oxacillin. Inoculum was prepared by diluting $0.5 \mathrm{McF}$ arland equivalent suspension of a strain with sterile normal saline to the concentration of $10^{4} \mathrm{CFU} / \mathrm{ml}$. The plates were spotinoculated and incubated at $35{ }^{\circ} \mathrm{C}$ for $24 \mathrm{~h}$. An oxacillin minimum inhibitory concentration (MIC) of $\leq 2 \mu \mathrm{g} / \mathrm{ml}$ indicated that the strain was susceptible and that of $>2 \mu \mathrm{g} / \mathrm{ml}$ resistant (NCCLS 2003).

\section{The mecA gene detection by PCR}

Staphylococcal DNA was isolated using chloroform: phenol extraction method (Sambrook et al 1989). The primers used for detection of the mecA gene were MecA1 (5'-GTA GAA ATG ACT GAA CGT CCG ATA A) and MecA2 (5'-CCA ATT CCA CAT TGT TTC GGT CTA A), as described earlier (Geha et al 1994). A Biometra DNA thermocycler was programmed for initial denaturation at $94^{\circ} \mathrm{C}$ for $4 \mathrm{~min} ; 30$ cycles of amplification (denaturation at $94{ }^{\circ} \mathrm{C}$ for $45 \mathrm{sec}$, annealing at $56^{\circ} \mathrm{C}$ for $45 \mathrm{sec}$, and extension at $72^{\circ} \mathrm{C}$ for $30 \mathrm{sec}$ ); and a final extension at $72{ }^{\circ} \mathrm{C}$ for $2 \mathrm{~min}$. To visualize, $10 \mu \mathrm{l}$ of the PCR amplicon was loaded in $2 \%$ agarose gel in TBE $(0.089 \mathrm{M}$ Tris, $0.089 \mathrm{M}$ boric acid, $0.002 \mathrm{MEDTA}$ ) containing $0.5 \mu \mathrm{l} / \mathrm{ml}$ of ethidium bromide and visualized by using UV transillumination at $300 \mathrm{~nm}$. DNA fragments of $310 \mathrm{bp}$ corresponded to the $m e c A$ gene.

\section{Results}

Of the 783 S. aureus strains (503 from outpatient departments [OPDs] and 280 from wards), 301 (38.44\%) - 187 from OPDs and 114 from wards - showed methicillin resistance in disc diffusion and MIC tests and were confirmed as MRSA by the mecA gene PCR. The remaining $482(61.56 \%)$ were MSSA. Table 1 shows the pattern of resistance shown by MRSA strains as well as compares its distribution in OPDs and wards. Resistance to penicillin was highest (97\%) followed by cotrimoxazole (95.68\%), chloramphenicol (92.36\%), and norfloxacin (90.7\%).

The resistance pattern of MRSA was somewhat varying between OPDs and wards for macrolides, chloramphenicol, tetracycline, cotrimoxazole, nitrofurantoin and betalactam/ betalactamase inhibitor combination; the pattern was more or less same for other antibiotics (Table 1).

Out of 301 MRSA isolates, 217 (72.1\%) were multidrug resistant, with 136 being resistant to more than three 
Table I Resistance pattern of MRSA against various antimicrobials and its relative distribution in OPDs and wards

\begin{tabular}{|c|c|c|c|}
\hline Antimicrobials & $\begin{array}{l}\text { Overall resistance } \\
(n=301)\end{array}$ & $\begin{array}{l}\text { Resistance in } \\
\text { OPDs }(n=187)\end{array}$ & $\begin{array}{l}\text { Resistance in } \\
\text { wards }(n=|| 4)\end{array}$ \\
\hline Penicillin & $97 \%(292)$ & $96.79 \%(\mid 8 I)$ & $97.37 \%(\mathrm{III})$ \\
\hline Gentamicin & $55.81 \%(168)$ & $55.6 \%(104)$ & $56.14 \%(64)$ \\
\hline Tobramycin & $53.49 \%(161)$ & $54.01 \%(101)$ & $52.63 \%(60)$ \\
\hline Amikacin & $41.53 \%(125)$ & $40.64 \%(76)$ & $42.98 \%(49)$ \\
\hline Netilmicin & $65.78 \%(198)$ & $65.24 \%(122)$ & $66.67 \%(76)$ \\
\hline Norfloxacin ${ }^{\mathrm{a}}$ & $90.7 \%(273)$ & $90.91 \%(170)$ & $90.35 \%(103)$ \\
\hline Ciprofloxacin & $75.75 \%(228)$ & $76.47 \%(143)$ & $75.56 \%(85)$ \\
\hline Chloramphenicol & $92.36 \%(278)$ & $90.91 \%(170)$ & $94.74 \%(108)$ \\
\hline Erythromycin & $68.77 \%(207)$ & $66.31 \%(124)$ & $72.81 \%(83)$ \\
\hline Tetracycline & $76.1 \%(229)$ & $73.79 \%(138)$ & $79.82 \%(91)$ \\
\hline Trimethoprim/Sulphamethoxazole & $95.68 \%(288)$ & $94.12 \%(176)$ & $98.25 \%(112)$ \\
\hline Nitrofurantoin ${ }^{a}$ & $58.14 \%(175)$ & $60.43 \%(113)$ & $54.4 \%(62)$ \\
\hline Vancomycin & $0.33 \%(I)$ & $0 \%$ & $0.88 \%(I)$ \\
\hline Cefoperazone/Sulbactam & $65.12 \%(196)$ & $67.91 \%(127)$ & $60.53 \%(69)$ \\
\hline
\end{tabular}

Note: ${ }^{a}$ Test done only for urine isolates.

Abbreviations: MRSA, methicillin-resistant Staphylcoccus aureus; OPD, outpatient departments.

antimicrobials except vancomycin. One MRSA strain was found to be resistant to all antibiotics including vancomycin (Table 2).

Frequency of isolating MRSA was maximum in cutaneous and wound specimens ( $42.2 \%$ ) followed by blood, respiratory specimens, and urine (Table 3).

\section{Discussion}

Studies show that the epidemiology of MRSA over different parts of India is not uniform. The present study reports $38.44 \%$ MRSA among $S$. aureus isolates, whereas an earlier study done in the same hospital here had shown a higher prevalence of $54.8 \%$ (Anupurba et al 2003). Some studies have reported comparable prevalence: $38.56 \%$ in Delhi (Mohanty et al 2004), 31.1\% in a multicenter study

Table 2 Multidrug resistance* in MRSA

\begin{tabular}{ll}
\hline Resistance to & MRSA (n = 30 I) \\
\hline $\begin{array}{l}\text { More than three nonvancomycin } \\
\text { antimicrobials }\end{array}$ & $45.18 \%(\mathrm{I} 36)$ \\
All antimicrobials except vancomycin & \\
All antimicrobials except vancomycin & $22.25 \%(67)$ \\
and cefoperazone/sulbactam & $4.31 \%(\mathrm{I})$ \\
All antimicrobials & \\
Total multidrug resistance & $0.033 \%(\mathrm{I})$ \\
\hline
\end{tabular}

Note: *MRSA strains which were resistant to three or more than three antibiotics tested were considered to be multidrug-resistant MRSA.

Abbreviation: MRSA, methicillin-resistant Staphylcoccus aureus. in Tamilnadu (Rajaduraipandi et al 2006), and 39.50\% in South Gujarat (Mulla et al 2007). In contrast, other studies have reported entirely different prevalence: $24 \%$ in Vellore (Pulimood et al 1996), 80.89\% in Indore (Verma et al 2000), $52.9 \%$ in Assam (Assadullah et al 2003), 19.56\% in Nagpur (Tahnkiwale et al 2002), and 24\% in Chandhigarh (Mehta et al 2007). Although it's extremely difficult to explain these conflicting data with regards to both time and place of study, the variation is probably due to differential clonal expansion and drug pressure in community.

Given the fact that staphylococci spread by direct or indirect person-to-person contact, the emergence of multidrug-resistant stains of MRSA is worrisome in the present therapeutic scenario. Multidrug resistance was defined as resistance of a MRSA strain towards three or more antibiotics at a given point of time. In the USA, some workers (Styers et al 2006) have reported multi-drug resistance rates of $67.8 \%$ (for inpatients) and $65 \%$ (for outpatients) in lower respiratory tract MRSA isolates. In Nigerian women, a total of 43 S. aureus out of 60 were found to be multidrug resistant (Onanuga et al 2005). We found a high percentage of multidrug-resistant MRSA $(72.1 \%)$ in our hospital. If we look into the Indian literature, it seems the burden of multi drugresistant-MRSA is increasing over time: for instance, $23.2 \%$ was reported by Majumder and colleagues in $2001 ; 32 \%$ by Anupurva and colleagues in 2003; and $63.6 \%$ by Rajaduraipandi and colleagues 2006 . The lesson is clear: MRSA surveillance and strict drug policy are of paramount importance, or else the threat will increase. 
Table 3 Frequency of S. aureus and MRSA in specimens

\begin{tabular}{lll}
\hline Clinical specimens & S. aureus $(\mathbf{n}=\mathbf{7 8 3})$ & MRSA ( $\mathbf{n = 3 0}$ I) \\
\hline Pus and wound specimens & $68.9 \%(540)$ & $42.2 \%(228)$ \\
Blood & $2.9 \%(23)$ & $34.8 \%(8)$ \\
Respiratory specimens & $3.3 \%(26)$ & $34.6 \%(9)$ \\
$\quad$ Mid stream & $20.0 \%(157)$ & $26.7 \%(42)$ \\
$\quad$ Catheterized & $2.4 \%(19)$ & $63.1 \%(12)$ \\
Urine & & \\
$\quad$ Bone aspirate & $\mathrm{I} .0 \%(8)$ & $12.5 \%(1)$ \\
CSF, ascetic fluid, EPF, HVS & $1.3 \%(10)$ & $10 \%(\mathrm{I})$ \\
\hline
\end{tabular}

Abbreviations: CSF, cerebrospinal fluid; EPF, expressed prostatic fluid; HVS, high vaginal swab; MRSA, methicillin-resistant Staphylcoccus aureus.

The MRSA strain that showed resistance to all antimicrobials including vancomycin was isolated from a 56-year-old male patient admitted in post-operative ward of our hospital. The zone of inhibition shown by this strain in response to vancomycin disc was less than $9 \mathrm{~mm}$; therefore we tentatively characterized this strain as vancomycin resistant $S$. aureus. Molecular investigation of the strain for the presence of $v a n A / B$ gene is needed to clarify its exact status.

Patterns of resistance shown by MRSA to Beta-lactams, aminoglycosides and quinolones are more or less identical in OPDs and wards, while the same to erythromycin, chloramphenicol, tetracycline, cotrimoxazole, nitrofurantoin, and betalactam/betalactamase inhibitor combination present certain level of difference between their distributions in OPDs and wards. This is a reflection of differential drug pressure.

Currently, the majority $(80 \%-90 \%)$ of $S$. aureus strains in communities are beta-lactamase producers hence resistant to penicillin and ampicillin (Paradisi et al 2001; Ang 2004). Recently more than 90\% isolates from South Maharashtra have been found resistant to ampicillin, tobramycin, penicillin, erythromycin, kanamycin and gentamicin, whereas only $39.1 \%$ of strains are resistant to methicillin (Kandle et al 2003). The choice is obviously oxacillin; however, fearing MRSA, clinicians may exploit vancomycin. Our study reports that antibiotics other than vancomycin - for instance, amikacin, tobramycin, gentamicin, cefoperazone/ sulbactam - can be promising if a susceptibility testing is done, reserving vancomycin for life-threatening infections. A retrospective study of bacterial isolates from cases of neonatal septicemia over a period of five years from Chandigarh, India, has also reported that netilmicin was the most effective drug for S. aureus (Agnihotri et al 2004).

Factors contributing to drug resistance in developing countries are myriad. Antibiotics are available without prescription at drug stores or even at general stores and injudiciously used in communities, animal husbandries, and fisheries. Traditional practitioners use allopathic drugs, and many practitioners who earn by selling medicines prescribe more drugs than necessary (Holloway 2000). In a study from five districts of Tamilnadu, India, 285 general practitioners and specialists believed that antibiotics are overprescribed: purulent discharge (65\%), antibiotic-resistance concerns (48\%), fever (40\%), and patient satisfaction (29\%) being the strong reasons for overprescription (Sivagnanam et al 2004). Poor quality antibiotics are produced at local levels, and patients show poor compliance to costly antimicrobials (Hart 1998). Therefore, there is no other way than to foil these malpractices, to constantly conduct microbiological surveillance like this, and follow infection control measures like hand washing and other aseptic techniques if we are to avoid therapeutic crisis resulting from multidrugresistant MRSA.

\section{Acknowledgments}

Hare Krishna Tiwari is thankful to the University Grant Commission, Kathmandu, Nepal for providing partial fellowship for this work. The authors report no conflicts of interest in this work.

\section{References}

Agnihotri N, Kaistha N, Gupta V. 2004. Antimicrobial susceptibility of isolates from neonatal septicemia. Jpn J Infect Dis, 57:273-75.

Ang JY, Ezike E, Asmar BI. 2004. Antibacterial resistance. Indian J Pediatr, 71:229-39.

Anupurba S, Sen MR, Nath G, et al. 2003. Prevalence of methicillin resistant Staphylococcus aureus in a Tertiary care Referral Hospital in Eastern UttarPradesh. Indian J Med Microbiol, 21:49-51.

Assadullah S, Kakru DK, Thoker MA, et al. 2003. Emergence of low level vancomycin resistance in MRSA. Indian J Med Microbiol, 21:196-8.

Barid D. 1996. Staphylococcus: Cluster-forming Gram-positive cocci, Chapter 11. In: Collee JG, Fraser AG, Marmion BP, et al. (eds). Mackie and McCartney Practical Medical Microbiology, 14th ed. New York: Churchill Livingstone.

Chambers HF. 2001. The changing epidemiology of Staphylococcus aureus? Emerg Infect Dis, 7:178-82.

Cosgrove SE, Sakoulas G, Perencevich EN, et al. 2003. Comparison of mortality associated with methicillin-resistant and methicillinsusceptible Staphylococcus aureus bacteremia: a meta-analysis. Clin Infect Dis, 36:53-9.

Değerli K, Özbakkaloğlu B, Sürücüoğlu S, et al. 2000. The susceptibility rates of Staphylococcus aureus strains to various antibiotics isolated from clinical specimens. Infek Derg, 14:87-90.

Gastmeier P, Sohr D, Geffers C, et al. 2002. Occurrence of methicillin resistant Staphylococcus aureus infections in German intensive care units. Infection, 30:198-202.

Geha DJ, Uhl JR, Gustaferro CA, et al. 1994. Multiplex PCR for identification of methicillin-resistant staphylococci in the clinical laboratory. J Clin Microbiol, 32:1768-72.

Hart CA, Kariuki S. 1998. Antimicrobial resistance in developing countries. BMJ, 317:647-50. 
Holloway K. 2000. Antimicrobial resistance: the facts. Essential Drug Monitor WHO, 28\&29:7-8.

Jevons MP. 1961. "Celbenin"-resistant staphylococci. Br Med J, 1:124-25.

Kandle SK, Ghatole MP, Takpere AY, et al. 2003. Bacteriophage typing and antibiotic sensitivity pattern of Staphylococcus aureus from clinical specimen in and around Solapur (South Maharashtra). J Commun Dis, $35: 17-23$.

Majumder D, Bordoloi JN, Phukan AC, et al. 2001. Antimicrobial susceptibility pattern among methicillin resistant Staphylococcus isolates in Assam. Indian J Med Microbiol, 19:138-40.

Mehta M, Dutta P, Gupta V. 2007. Bacterial isolates from burn wound infections and their antibiograms: A eight-year study. Indian J Plast Surg, 40:25-8.

Mohanty S, Kapil A, Dhawan B, et al. 2004. Bacteriological and antimicrobial susceptibility profile of soft tissue infections from Northern India. Indian J Med Microbiol, 58:10-15.

Mulla S, Patel M, Shah L, et al. 2007. Study of antibiotic sensitivity pattern of methicillin-resistant Staphylococcus aureus. Indian J Crit Care Med, 11:99-101.

[NCCLS] National Committee for Clinical Laboratory Standards. 2003. Methods for dilution antimicrobial susceptibility tests for bacteria that grow aerobically: Approved Standard M7-A6. NCCLS, Wayne, PA, USA.

[NCCLS] National Committee for Clinical Laboratory Standards. 2004. Performance standards for antimicrobial disc susceptibility testing: Fourteenth Informational Supplement M100-S14. NCCLS, Wayne, PA, USA.

Onanuga A, Oyi AR, Olayinka BO, et al. 2005. Prevalence of communityassociated multi-resistant Staphylococcus aureus among healthy women in Abuja, Nigeria. African J Biotech, 4:942-45.

Paradisi F, Corti G, Messeri D. 2001. Antibiotic therapy. Antistaphylococcal (MSSA, MRSA, MSSE, MRSE) antibiotics. Med Clin North Am, 85:1-17.

Pulimood TB, Lalitha MK, Jesudason MV. 1996. The spectrum of antimicrobial resistance amongst MRSA in a tertiary care centre in India. Ind J Med Res, 103:212-5.
Rajaduraipandi K, Mani KR, Panneerselvam K, et al. 2006. Prevalence and antimicrobial susceptibility pattern of methicillin resistant Staphylococcus aureus: A multicentre study. Ind J Med Microbiol, 24:34-8.

Red Book. 2003. Report of the Committee on Infectious Diseases, 26th ed. Staphylococcal Infections, 561-73.

Saha B, Singh AK, Ghosh A, et al. 2008. Identification and characterization of a vancomycin-resistant Staphylococcus aureus isolated from Kolkata (South Asia). J Med Microbial, 57:72-9.

Sambrook J, Fritsch EF, Maniatis T. 1989. Molecular Cloning: a Laboratory Manual. (2nd ed). New York: Cold Spring Harbor Laboratory Press.

Santos SI, Mato R, de Lencastre H, et al. 2000. CEM/NET Collaborators and the International Collaborators. Patterns of multidrug resistance among methicillin-resistant hospital isolates of coagulase-positive and coagulase-negative staphylococci collected in the international multicenter study RESIST in 1997 and 1998. Microb Drug Resist, 6:199-211.

Sivagnanam G, Thirumalaikolundusubramanian P, Mohanasundaram J, et al. 2004. A survey on current attitude of practicing physicians upon usage of antimicrobial agents in southern part of India. Med Gen Med, 6:1.

Styers D, Sheehan DJ, Hogan P, et al. 2006. Laboratory-based surveillance of current antimicrobial patterns and trends among Staphylococcus aureus: 2005 status in the United States. Ann Clinl Microbiol Antimicrobl, 5:2.

Tahnkiwale SS, Roy S, Jalgaonkar SV. 2002. Methicillins resistance among isolates of Staphylococcus aureus: antibiotic sensitivity pattern and phage typing. Ind J Med Sci, 56:330-4.

Tiwari HK, Sen MR. 2006. Emergence of VRSA from a tertiary care hospital from northern part of India. BMC Infect Dis, 6:156.

Verma S, Joshi S, Chitnis V, et al. 2000. Growing problem of methicillin resistant staphylococci: Indian Scenario. Indian J Med Sci, 54:535-40.

Voss A, Doebbeling BN. 1995. The worldwide prevalence of methicillin resistant Staphylococcus aureus. Int J Antimicrob Agents, 5:101-6. 
